\title{
Crescentic IgA nephropathy following bone fracture
}

\author{
Ayman Karkar, Reda Ghacha and Mohammed Abdelrahman \\ Department of Nephrology, Kanoo Kidney Centre, Dammam Medical Complex, Dammam, Saudi Arabia
}

\begin{abstract}
Immunoglobulin A (IgA) nephropathy is the commonest form of primary glomerulonephritis with variable clinical presentation. It has been associated with several infectious and non-infectious diseases but with only few reported cases following traumatic bone fracture. The present case report describes a 55 years old male patient who developed acute kidney injury within 3 months following bone fracture. Urine examination showed microscopic haematuria and proteinuria together with rapid deterioration in renal function. Light microscopic examination of kidney biopsy sections showed glomerular mesangial proliferation with fibro-cellular crescent formation in few glomeruli, two glomeruli were sclerosed, in addition to interstitial inflammation and tubular atrophy. Immunofluorescence microscopy showed mesangial IgA and C3 deposits. The renal function improved substantially following a course of steroids and mycophenolate mofetil without dialysis support. The development of acute $\operatorname{IgA}$ nephropathy is possibly followed the incident of traumatic bone fracture.
\end{abstract}

\section{Introduction}

Immunoglobulin A (IgA) nephropathy is the most common form of primary glomerulonephritis that can lead to progressive renal failure in a substantial number of patients [1-4]. The clinical manifestation of IgA nephropathy is highly variable, ranging from non-progressive benign disease to variably progressive course leading ultimately to end-stage renal disease $[5,6]$. IgA nephropathy can manifest as asymptomatic microscopic haematuria, gross haematuria, nephritic syndrome, nephrotic syndrome or acute renal injury from heavy glomerular haematuria with tubular occlusion and/or damage by red cells or from crescentic glomerulonephritis [7]. Although patients with IgA nephropathy have genetic susceptibility [8], IgA nephropathy has been associated with several diseases including viral [9-11] and bacterial [12,13] infections, autoimmune diseases [14], renal cell carcinoma [15], leukemia and lymphoma [16], Hodgkin's disease [17], keloid scar due to burn injury [18], high-voltage electrical burn [19], overexposure to cadmium fumes [20] and osteomyelitis [21]. Here, a patient presented with acute IgA nephropathy is reported following traumatic bone fracture, where more than a decade ago five similar cases were reported [22].

\section{Case report}

A 55 years old male patient sustained multiple injuries after allegedly involved in a motor vehicle accident. He required intubation and mechanical ventilation following admission to intensive care unit (ICU). The patient underwent several surgical procedures involving maxillo-facial region and open reduction and internal fixation for long bone fractures and fixation of hip dislocation. He achieved excellent surgical recovery, maintained normal renal function and moved to rehabilitation ward.

Renal function tests and urine analysis were unremarkable at the time of admission to ICU. During his admission in ICU, he was intubated and mechanically ventilated, pupils were equal in size and reacting to light, and had ecchymosis around his eyes. He was afebrile with regular pulse rate of $112 / \mathrm{min}$, blood pressure $160 / 70 \mathrm{~mm} \mathrm{Hg}$, oxygen saturation was $100 \%$ with Fio 2 35\%. No abnormalities were detected on cardiovascular and chest examination, and there was no lower limb oedema. Patient was hemodynamically stable and maintained adequate urine output of 1.5-2.0 liters/day. His serum creatinine was $0.8 \mathrm{mg} / \mathrm{dl}$ (eGFR $101 \mathrm{ml} / \mathrm{min}$ ), urea $31 \mathrm{mg} / \mathrm{dl}$ and urine analysis showed no albuminuria or glucosuria, pus cells 2-3/ hpf and RBC $0-1 / \mathrm{hpf}$. However, during his stay in ICU, there were two episodes of macroscopic haematuria which were attributed to Foley's catheterisation and low molecular weight heparin. CT scan revealed fracture bilateral zygomatic bone and had bilateral hemosinus. Echocardiography revealed a normal study. His post-recovery serum creatinine was $0.8 \mathrm{mg} / \mathrm{dl}$ and urea $30 \mathrm{mg} / \mathrm{dl}$.

Three months after hospitalization the patient's laboratory investigations revealed abnormal renal function tests. His urine analysis showed $15-20$ pus cells, $3+$ proteinuria and many $\mathrm{RBCs} / \mathrm{hpf}$. The increases in pus cells indicated urinary tract infection. His serum creatinine was doubled to $1.2 \mathrm{mg} / \mathrm{dl}$ (eGFR $68 \mathrm{ml} / \mathrm{min}$ ) and continued to rise reaching $3.5 \mathrm{mg} / \mathrm{dl}$ (eGFR $19 \mathrm{ml} / \mathrm{min}$ ) in the following ten days, when he was referred for nephrology consultation.

The patient was asymptomatic with normal vital signs (pulse 78/ min, BP 132/78 mmHg, RR $18 / \mathrm{min}$, temperature $37^{\circledR} \mathrm{C}$ ) and in stable general condition. He had a history of controlled type 2 diabetes mellitus for 10 years (HbAlc 7\%) and hypertension for 3 years, but there was no past history of renal disease or family history of kidney disease. There was no recent systemic viral or bacterial infection, no recent blood or fluid loss, and no recent exposure to nephrotoxic

Correspondence to: Ayman Karkar, Department of Nephrology, Kanoo Kidney Centre, Dammam Medical Complex, Kingdom of Saudi Arabia,Tel:+966 13891 2710, Fax:+966 13891 2610, E-mail: aymankarkar@yahoo.com

Key words: ACE inhibitor, acute renal injury, bone fracture, crescentic glomerulonephritis, IgA nephropathy, immunosuppressive therapy

Received: December 17, 2016; Accepted: January 09, 2017; Published: January 12,2017 
drugs or radiocontrast agents. Funduscopic examination revealed no diabetic or hypertensive retinopathy. Ultrasound examination showed normal size kidneys with no focal dilated collecting system and no significant post-residual urine volume. His initial urine analysis showed RBCs 3-4/hpf and albumin was +++ . Serum creatinine was $4.5 \mathrm{mg} / \mathrm{dl}$ (eGFR $14 \mathrm{ml} / \mathrm{min}$ ) and proteinuria $400 \mathrm{mg} / 24$ hour urine collection. Serum IgA level was within normal range $(68-432 \mathrm{mg} / \mathrm{dl})$. His serology reports revealed negative ANA, anti-DNA, ANCA, and anti-GBM antibody, but slightly decreased C3 and normal levels of C4. Immunoglobulins and cryogolbulins were within normal limits, HBsAg, antibodies to HCV and HIV were all negative. Repeated urine analysis showed 25 pus cells, $3+$ proteinuria and many RBCs/hpf. The pus cells, and RBCs, indicated urinary tract infection, possibly due to Foley's catheterisation. Urine culture and sensitivity revealed Proteus bacterial growth which was sensitive to imepenem. Repeated urine analysis showed no pus cells and urine culture showed no growth following treatment with a course of imepenem. His blood pressure was controlled $(127 / 78 \mathrm{mmHg})$ with angiotensin converting enzyme inhibitor (Perindopril 5mg OD). The sudden, rapid and unexplained deterioration in renal function, and the absence of diabetic and hypertensive retinopathy, the decision for a diagnostic renal biopsy was taken. The patient was bed-bound due to fixed flexion deformities of lower limbs and deformity of left arm, and it was difficult to perform a renal biopsy in a suitable position. However, a week later and under effect of sedation, a real time renal biopsy was performed in right lateral position under ultrasound guidance. Post-procedural condition of the patient was uneventful. Light microscopy showed 32 glomeruli with prominent mesangial proliferation, fibrocellular crescent formation in 4 glomeruli, 2 glomeruli were sclerosed, and there was moderate degree of interstitial inflammation and tubular atrophy (Figure 1a and 1b). The immunofluorescent stained sections showed focal mesangial and capillary wall deposits for IgA and C3 (Figure 2).

Methylprednisolone (1gm daily) was injected intravenously for 3 days followed by $60 \mathrm{mg} /$ day oral prednisolone and mycophenolate mofetil $1 \mathrm{gm}$ twice daily. This treatment resulted in rapid improvement in renal function, where proteinuria came to less than $150 \mathrm{mg} / 24$ hours and serum creatinine dropped from $4.5 \mathrm{mg} / \mathrm{dl}$ (eGFR $14 \mathrm{ml} / \mathrm{min}$ ) to $2.6 \mathrm{mg} / \mathrm{dl}$ (eGFR $27 \mathrm{ml} / \mathrm{min}$ ), without dialysis support despite the presence of few crescentic and sclerosed glomeruli, and the interstitial inflammation with tubular atrophy. The patient was maintained on $5 \mathrm{mg} /$ day prednisolone and $500 \mathrm{mg}$ twice daily mycophenolate mofetil before discharge. Unfortunately, patient didn't maintain his outpatient clinic follow up appointments and was not seen again.

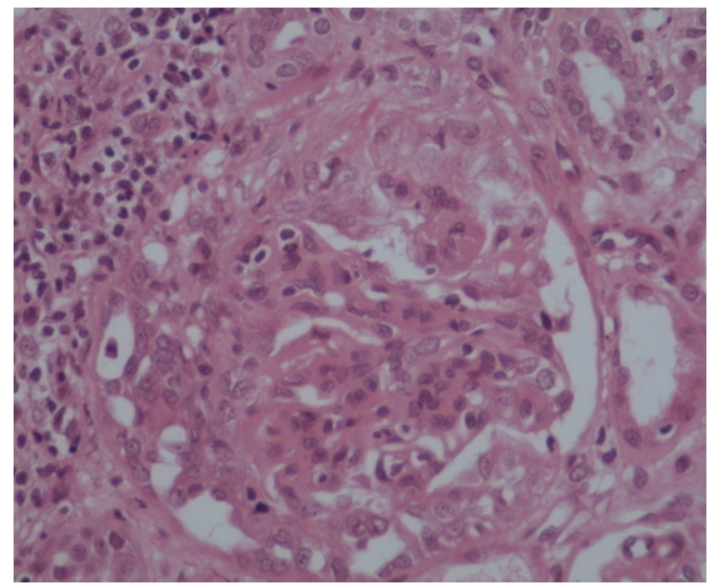

Figure 1a. Light microscopy: Fibro-cellular crescent formation and mesangial proliferation.

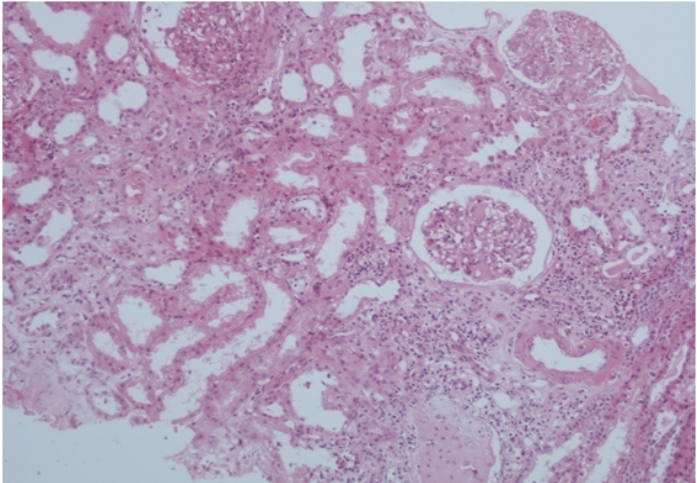

Figure 1b. Light microscopy: Sclerosed glomeruli with interstitial inflammation and tubular atrophy.

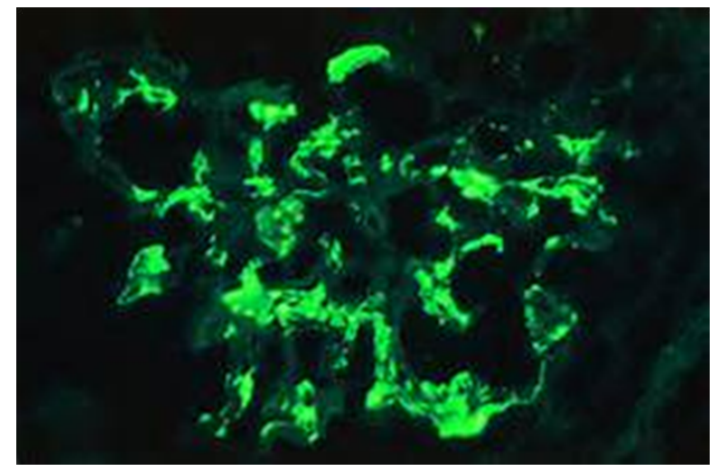

Figure 2. Immunofluorescent stained sections showed focal mesangial and capillary wall deposits for IgA.

\section{Discussion}

Acute crescentic IgA nephropathy is an uncommon presentation occurring in less than $5 \%$ of patients. This reported case, with normal serum level of $\operatorname{IgA}$, presents a rare association between bone fracture and IgA nephropathy. It also presents a late onset of disease, where IgA nephropathy is more common in the $2^{\text {nd }}$ and $3^{\text {rd }}$ decades. Its time and mode of acute onset and latent period after fracture are similar to five cases reported more than a decade ago [22]. However, our reported case did not complicate or was associated with osteomyelitis, infectious or non-infectious complications, as it has been reported in other similar cases $[21,22]$. Furthermore, there was no skin rash, arthritis or symptoms of disorders which are commonly associated with IgA nephropathy like Henoch-Schoenlein purpura, coeliac disease, dermatitis herpetiformis, HIV, ankylosing spondylitis and chronic hepatitis $[23,24]$.

The acute IgA nephropathy in this reported case is likely to be due to post traumatic fracture, as there was no previous history (or family history) of haematuria, proteinuria, renal disease or systemic illness, and there was no documented evidence of associated viral and/or bacterial infection. Furthermore, there was no immediate cause of acute kidney injury such as fluid or significant blood loss, exposure to nephrotoxic drugs or radiocontrast agents. It is possible that due to insidious onset of the disease, the correlation between IgA nephropathy and bone fracture has previously been overlooked. The sudden and rapid deterioration of renal function, and the histological picture including the presence of crescents formation, is suggestive of acute crescentic IgA nephropathy.

Primary glomerulonephritis, such as IgA nephropathy, has 
been reported to be superimposed on a background of diabetic glomerulosclerosis in patients with type 1 and 2 diabetes mellitus $[25,26]$. This could be a possibility in this reported case, though patient's diabetes mellitus was well-controlled (HbAlc 7\%, no proteinuria, normal renal function and no diabetic retinopathy). Furthermore, histologic evaluation disclosed prominent mesangial proliferation, interstitial inflammation and tubular atrophy, but not the presence of thickened glomerular basement membranes or nodular sclerosis. The histology also revealed four glomeruli with fibrocellular crescent formation but only two with glomerulosclerosis (out of 32 glomeruli). The immunofluorescence studies showed focal mesangial and capillary wall deposits for IgA and C3.

Despite the advancements and achievements in basic and clinical research, it is not clear how a latent period of post fracture can lead to development of acute crescentic IgA nephropathy [27,28]. It is tempting, however, to speculate that sequestrated antigen and/or exposure to the immunogenic epitope of an endogenous sequestrated antigen, following trauma and/or bone surgery, may have provoked an autoimmune disease with increased titres of circulating polymeric IgA1 (pIgA1) antibodies $[6,7,21,22]$. This effect is possibly accentuated by increased release of pIgA1 plasma cell numbers from bone marrow of the fractured bones [7]. The plasma levels of IgA in this case, however, were within normal limits; where plasma levels of $\operatorname{IgA}$ are only raised in about half of cases and the raised levels occurs in other conditions [6].

The current management of patients with acute crescentic rapidly progressive IgA nephropathy includes steroids [29-31] and cytotoxic drugs $[32,33]$, though overall renal survival in crescentic IgA nephropathy is significantly inferior to that in other forms of crescentic glomerulonephritis, including systemic vasculitis and Good pasture's disease [7,34]. The use of high dose of intravenous methylprednisolone followed by oral prednisolone and mycophenolate mofetil, in this reported case, was very effective in ameliorating the renal function deterioration and in inducing rapid recovery without dialysis support despite the presence of crescentic glomeruli together with interstitial inflammation and tubular atrophy. Interestingly, there was no correlation between the degree of proteinuria and worsening histopathology and the response to therapy, which is a similar finding reported in earlier cases [35-37].

In conclusion, this is a case of crescentic IgA nephropathy in a 55 years old male patient who developed acute kidney injury and rapid deterioration of renal function within 3 months following bone fracture. Although serum level of IgA was normal, histological findings showed mesangial proliferation and glomerular IgA and C3 deposition. In the absence of any associated diseases and/or risk factors, the development of acute crescentic IgA nephropathy is possibly followed the incident of traumatic bone fracture. Steroids and cytotoxic drugs were effective in ameliorating the renal function deterioration and in inducing rapid recovery without dialysis support.

\section{Conflict of interest}

\section{No conflict of interest.}

\section{References}

1. D’Amico G, Colasanti G, Barbiano di Belgioioso G, Fellin G, Ragni A, et al. (1987) Long-term follow-up of IgA mesangial Nephropathy: Clinico-histological study in 374 patients. Semin Nephrol 7: 355-358. [Crossref]

2. Galla JH (1995) IgA nephropathy. Kidney Int 47: 377-387. [Crossref]

3. Radford MG Jr1, Donadio JV Jr, Bergstralh EJ, Grande JP (1997) Predicting renal outcome in IgA nephropathy. J Am Soc Nephrol 8: 199-207. [Crossref]
4. Lv J, Yang Y, Zhang H, Chen W, Pan X, et al. (2013) Prediction of outcomes in crescentic IgA nephropathy in a multicenter cohort study. J Am Soc Nephrol 24: 21182125. [Crossref]

5. Feehally J, Cameron JS (2011) IgA nephropathy: progress before and since Berger. $\mathrm{Am}$ J Kidney Dis 58: 310-319. [Crossref]

6. Wyatt RJ, Julian BA (2013) IgA nephropathy. N Engl J Med 368: 2402-2414. [Crossref]

7. Barratt J, Feehally J (2005) IgA nephropathy. J Am Soc Nephrol 16: 2088-2097. [Crossref]

8. Magistroni R, D'Agati VD, Appel GB, Kiryluk K (2015) New developments in the genetics, pathogenesis, and therapy of IgA nephropathy. Kidney Int 88: 974-989. [Crossref]

9. Ortmanns A, Ittel TH, Schnitzler N, Handt S, Helmchen U, et al. (1998) Remission of IgA nephropathy following treatment of cytomegalovirus infection with ganciclovir. Clin Nephrol 49: 379-384.

10. Cheema SR, Arif F, Charney D, Meisels IS (2004) IgA-dominant glomerulonephritis associated with hepatitis A. Clin Nephrol 62: 138-143. [Crossref]

11. Upadhaya BK1, Sharma A, Khaira A, Dinda AK, Agarwal SK, et al. (2010) Transient IgA nephropathy with acute kidney injury in a patient with dengue fever. Saudi $J$ Kidney Dis Transpl 21: 521-525. [Crossref]

12. Siegelmann N, Abraham AS, Rudensky B, Shemesh O (1992) Brucellosis with nephrotic syndrome, nephritis and IgA nephropathy. Postgrad Med J 68: 834-836. [Crossref]

13. Koyama A, Sharmin S, Sakurai H, Shimizu Y, Hirayama K, et al. (2004) Staphylococcus aureus cell envelope antigen is a new candidate for the induction of IgA nephropathy. Kidney Int 66: 121-132. [Crossref]

14. Singri N, Gleason B, Flamm SL, Kanwar YS, Ghossein C (2004) Secondary IgA nephropathy presenting as nephrotic syndrome with glomerular crescentic changes and acute renal failure in a patient with autoimmune hepatitis. J Nephrol 17: 125-129. [Crossref]

15. Abu-Romeh SH, al-Adnani MS, Asfar S (1988) Renal cell carcinoma presenting with acute renal failure and IgA glomerulonephritis. Nephron 50: 169-170. [Crossref]

16. Motoyama O1 Kojima Y, Ohara A, Tsukimoto I, Ishikawa Y, et al. (2008) IgA nephropathy associated with leukemia and lymphoma: report of two cases. Clin Exp Nephrol 12: 140-143. [Crossref]

17. Bergmann J, Buchheidt D, Waldherr R, Maywald O, van der Woude FJ, et al. (2005) IgA nephropathy and hodgkin's disease: a rare coincidence. Case report and literature review. Am J Kidney Dis 45: e16-19. [Crossref]

18. Tanaka H, Waga S (2003) Acute IgA nephropathy following keloid scar formation due to burn injury. Clin Nephrol 60: 440-441. [Crossref]

19. Wang Y, Tang HT, Xia ZF, Wang GY (2009) Acute IgA nephropathy following highvoltage electrical burn injury. Clin Nephrol 71: 588-589. [Crossref]

20. Nogué S, Sanz-Gallén P, Torras A, Boluda F. (2004) Chronic overexposure to cadmium fumes associated with IgA mesangial glomerulonephritis. Occup Med (Lond) 54: 265267.

21. Tevlin MT, Wall BM, Cooke CR (1992) Reversible renal failure due to IgA nephropathy associated with osteomyelitis. Am J Kidney Dis 20: 185-188. [Crossref]

22. Takebayashi S, Hisano S, Sasatomi Y (1999) Acute IgA nephritis following bone fracture: a study of five cases. Clin Nephrol 52: 188-190. [Crossref]

23. Haas M (1997) Histologic subclassification of IgA nephropathy: a clinicopathologic study of 244 cases. Am J Kidney Dis 29: 829-842. [Crossref]

24. Alwar AJ (1982) Schonlein-Henoch syndrome: a case report and literature review. East Afr Med J 59: 357-360. [Crossref]

25. Rob G, Ueda Y, Ito S, Kohli R, Min I, et al. (1992) The Occurrence of IgA-Nephropathy in Patients with Diabetes Mellitus May Not Be Coincidental: A Report of Five Cases. Am J Kidney Dis 3: 255-260.

26. von Orfila C, De Lepert JC, van Modesto A, van Pipy B, Suc JM. (1998) IgA Nephropathy Complicating Diabetic Glomerulosclerosis. Nephron 3: 79. [Crossref]

27. Boyd JK, Barratt J (2010) Immune complex formation in IgA nephropathy: CD89 a 'saint' or a 'sinner'? Kidney Int 78: 1211-1213. [Crossref]

28. Glassock RJ (2011) The pathogenesis of IgA nephropathy. Curr Opin Nephrol Hypertens 20: 153-160. [Crossref] 
29. Bolton WK. Sturgill BC. (1989) Methylprednisolone therapy for acute crescentic rapidly progressive glomerulonephritis. Am J Nephrol 9: 368-375. [Crossref]

30. Itami N, Akutsu Y, Kusunoki Y, Tochimaru H, Takekashi Y (1989) Does methylprednisolone pulse therapy deteriorate the course of rapidly progressive IgA nephropathy? Am J Dis Child 143: 441-442. [Crossref]

31. Tesar V, Troyanov S, Bellur S, Verhave JC, Cook HT, et al. (2015) Corticosteroids in IgA Nephropathy: A Retrospective Analysis from the VALIGA Study. $J$ Am Soc Nephrol 26: 2248-2258. [Crossref]

32. Floege J, Eitner F (2010) Combined immunosuppression in high-risk patients with IgA nephropathy? J Am Soc Nephrol 21: 1604-1606. [Crossref]

33. Floege J, Rauen T (2016) Immunosuppression in IgA nephropathy: how certain are we? Kidney Int 89: 9-11. [Crossref]
34. Bolton WK1 (2000) Treatment of glomerular diseases: ANCA-negative RPGN. Semin Nephrol 20: 244-255. [Crossref]

35. Boyce NW, Holdsworth SR, Thomson NM, Atkins RC (1986) Clinicopathological associations in mesangial IgA nephropathy. Am J Nephrol 6: 246-252. [Crossref]

36. Tumlin JA, Lohavichan V, Hennigar R (2003) Crescentic proliferative IgA nephropathy: Clinical and histologic response to methylprednisolone and intravenous cyclophosphamide. Nephrol Dial Transplant 18: 1321-1329. [Crossref]

37. Lee MJ, Kim SJ, Oh HJ, Ko KI, Koo HM, et al. (2014) Clinical implication of crescentic lesions in immunoglobulin A nephropathy. Nephrol Dial Transplant 29: 356364. [Crossref]

Copyright: (C2017 Karkar A. This is an open-access article distributed under the terms of the Creative Commons Attribution License, which permits unrestricted use, distribution, and reproduction in any medium, provided the original author and source are credited. 